\title{
Explorando nuevos formatos para vídeos educativos
}

Universic Politécni de Carta

(c) $\frac{1}{\mathrm{GV}}$

Juan Medina Molina

Departamento de Matemática Aplicada y Estadística Universidad Politénica de Cartagena 


\section{Grabando vídeos educativos desde 2005}

Mi objetivo es complementar la labor que realiza el profesor en el aula, y que aprenda mucho más. 


\section{Vídeos que se publican en YouTube}

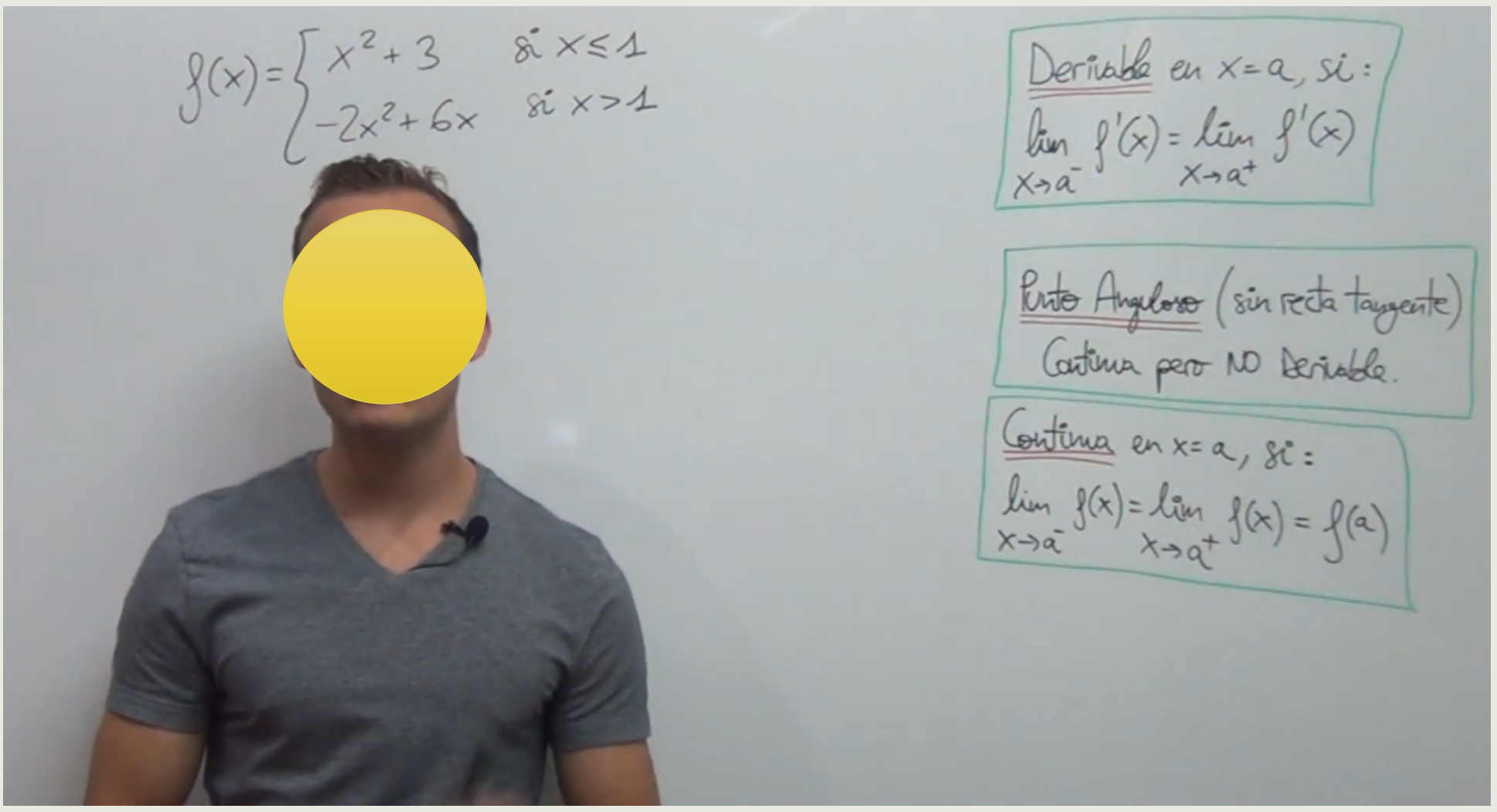

Fuente: YouTub 


\section{Vídeos que se publican en YouTube}

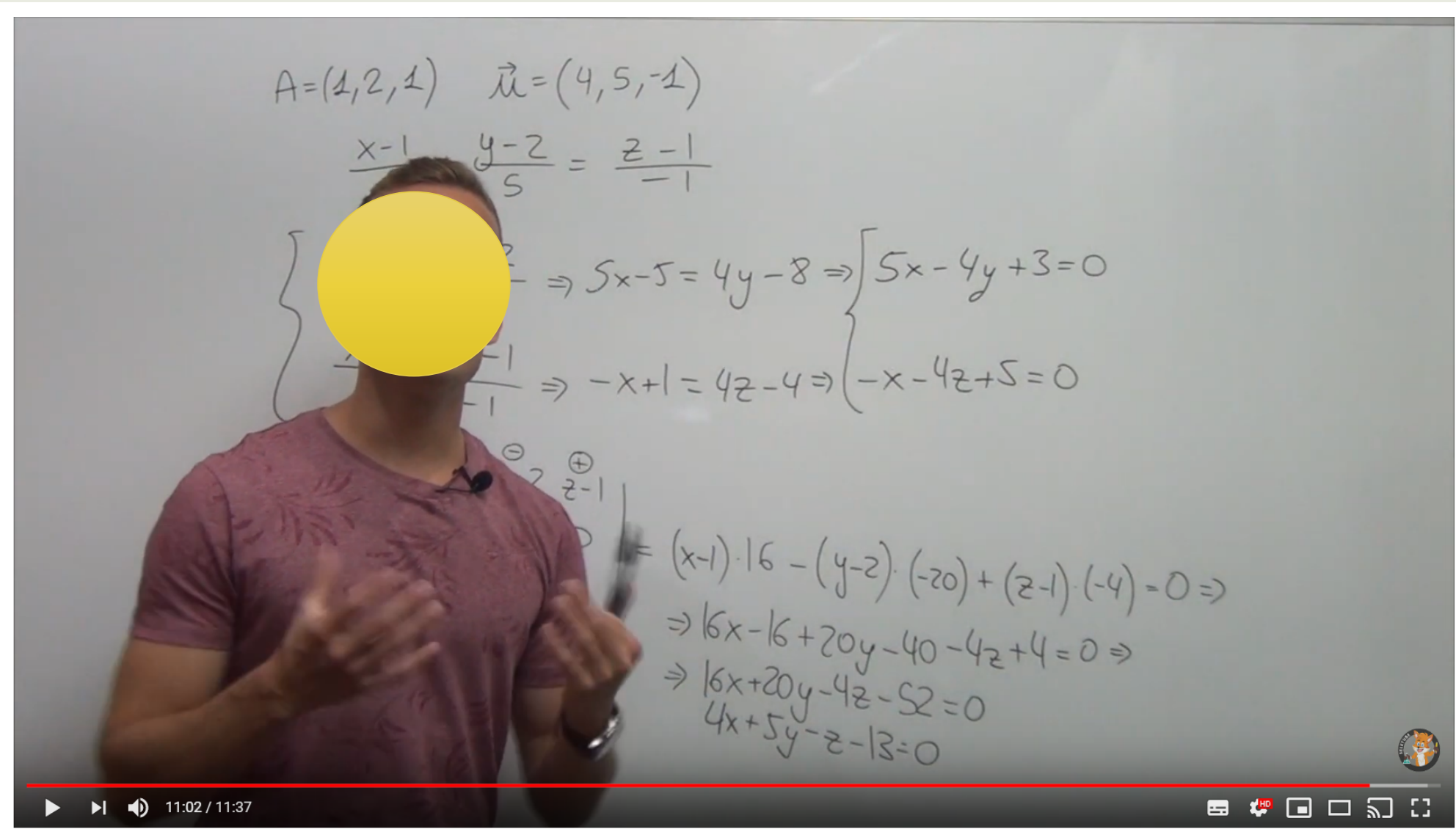

Ecuaciones de la Recta en el Espacio Ejercicios Resueltos Vectorial, Paramétrica, Continua, General 79 visualizaciones

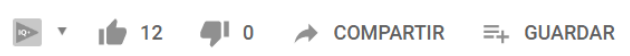

Fuente: YouTub 
Vídeos que se publican en YouTube

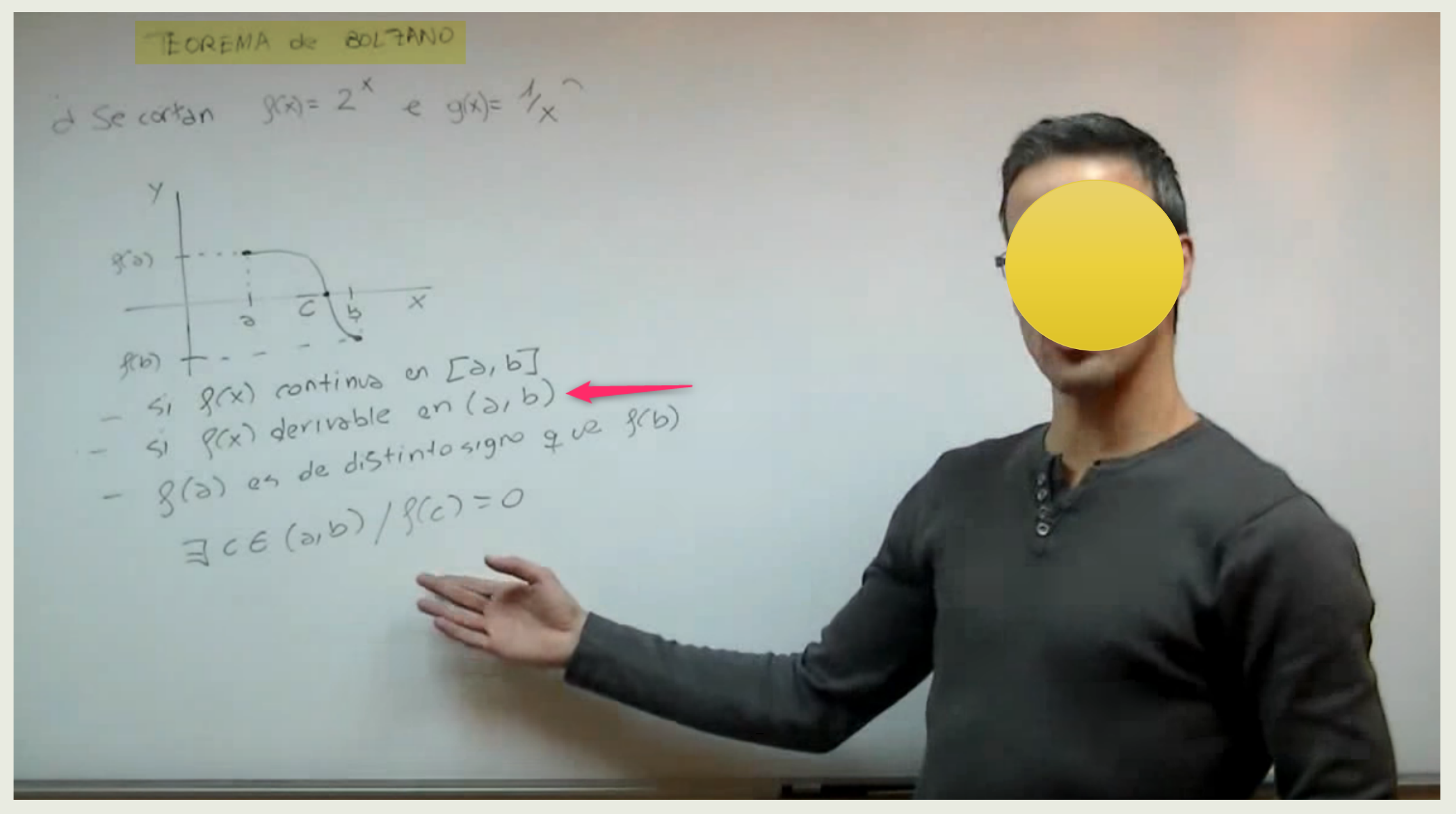

Fuente: YouT 


\section{Vídeos que se publican en YouTube}

\section{YouTube ${ }^{\mathrm{ES}}$}

Página principal

Tendencias

Suscripciones

Biblioteca

Historial

Ver más tarde

Vídeos favoritos

Curso de logarit...

Mostrar más

Q

企 FILTRAR

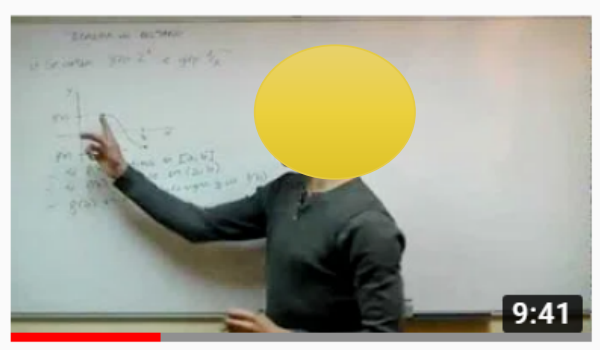

Teorema de BOLZANO BACHILLERATO matematicas

unicoos $\bullet 366$ mil visualizaciones $\cdot$ Hace 7 años $•$

Si este video te ayudó y quieres que unicoos siga creciendo, SUSCRíBETE, haz click en "Me gusta" y COMPÁRTELO. Si también ...

Teorema de Bolzano 01 ejercicios resueltos

profesor10demates $\bullet 66$ mil visualizaciones $\cdot$ Hace 4 años .

Teorema de Bolzano, ejercicios resueltos, explicación y ejemplos http://goo.gl/AzNcjv Lista http://goo.gl/LLGH4Q SUSCRIBETE..

Fuente: You

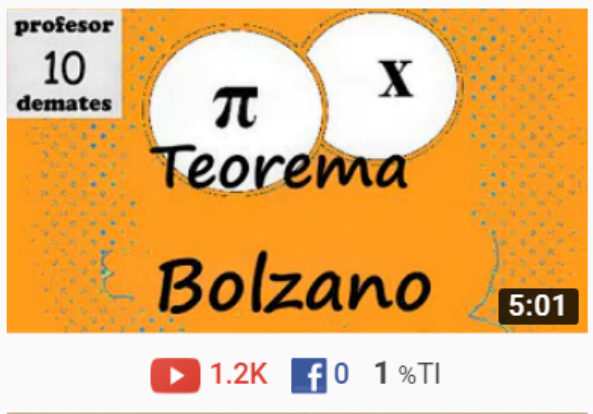




\section{Vídeos que se publican en YouTube}

TEOREMA de ROLLE

Si $f(x)$ es continua en $[a, b]$, derivable en $(a, b)$ y $\rho(a)=\rho(b)=0$

$\rightarrow \exists c \in(\partial, b) / \rho^{\prime}(c)=0$

$\rho(x)=x-x^{3}$ dc en $[-1,0]$ y $[0,1]$ ?
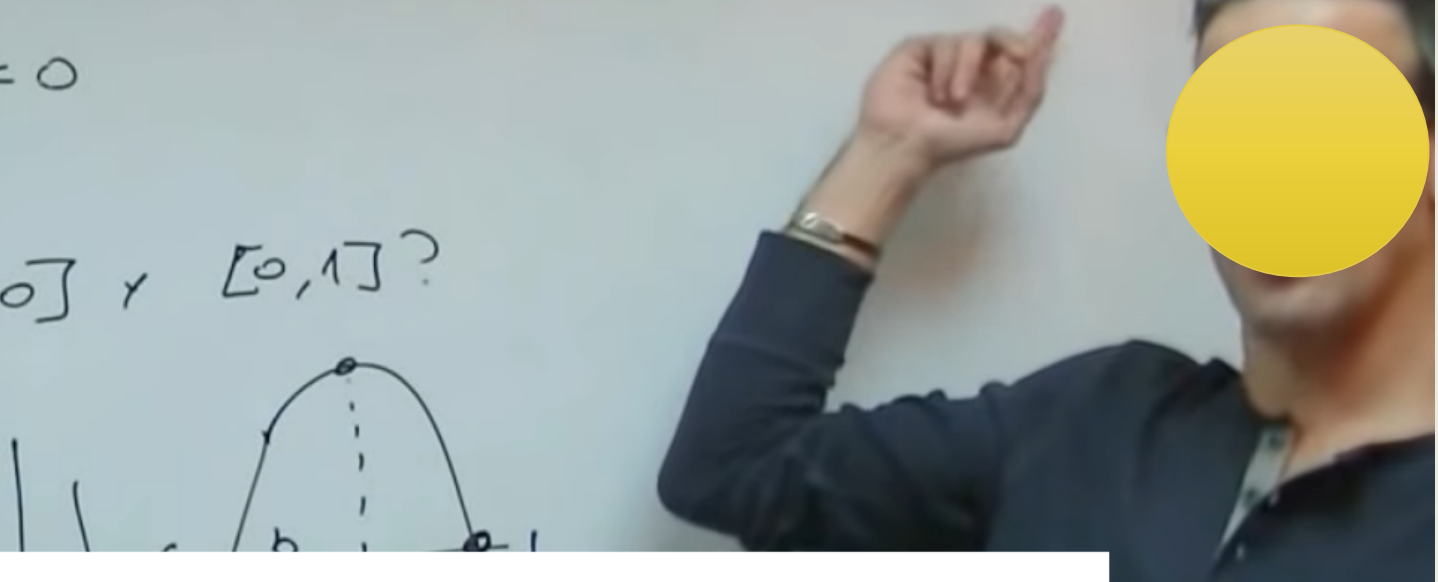

FE DE ERRORES para ver si estáis atentos ;-)

Con que $f(a)=f(b)$ es suficiente. No necesariamente tiene que ser 0 . La errata del libro donde busqué el teorema la trasladé a mi video. Sorry!!!

Fuente: 


\section{Vídeos que se publican en YouTube}

- Youtube ${ }^{\mathrm{ES}}$

Página principal

Tendencias

Suscripciones

Biblioteca

Historial

Ver más tarde

Vídeos favoritos

Curso de logarit..

Mostrar más

Competidores

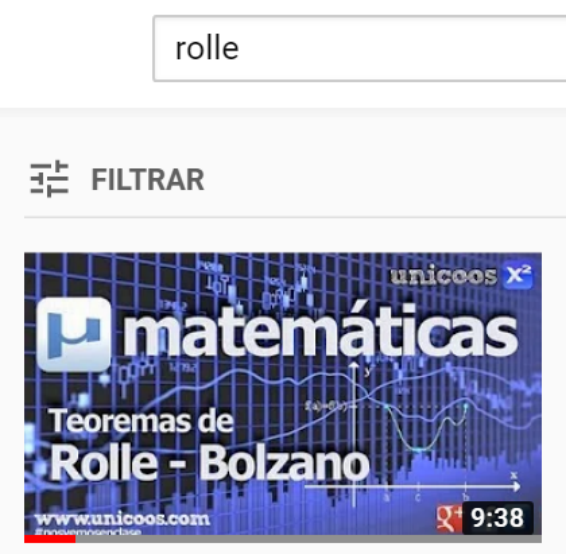

D $4.7 \mathrm{~K}$ ff $1 \% \mathrm{TI}$

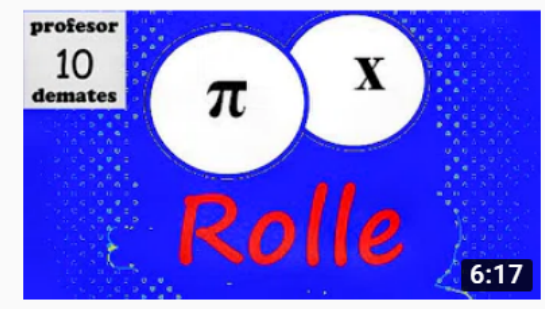

D 757 ffo $1 \% \mathrm{TI}$

卡 FILTRAR
Teorema de ROLLE BACHILLERATO matematicas derivadas

unicoos $\bullet 1.320 .028$ suscriptores 417 mil visualizaciones $\cdot$ Hace 7 años $\cdot 98 \%$

Si este video te ayudó y quieres que unicoos siga creciendo, SUSCRÍBETE, haz click en "Me gusta" y COMPÁRTELO. Si también ..
Teorema de Rolle ejercicios resueltos 01

profesor10demates $\bigcirc 293.482$ suscriptores 52 mil visualizaciones • Hace 2 años • $97 \%$

Teorema de Rolle ejercicios resueltos todo sobre funciones y teoremas en : http://goo.gl/ZicQSx

Comprueba que la función $\mathrm{f}(\mathrm{x})$...

Fuente: 


\section{lasmatematicas.es}

Cuando entran en juego conceptos matemáticos, propiedades y demostraciones, ..., SURGEN PROBLEMAS

En YouTube no se tiene en cuenta ningún criterio académico a la hora de mostrar los contenidos... Hasta ahora... 


\section{lasmatematicas.es}

Vídeos mecánicos, recetas: cómo hacer ejercicios sin entender nada,..., TRIUNFAN en YouTube. 


\section{lasmatematicas.es}

Muchos estudiantes solo "aprenden" matemáticas en YouTube, ignorando a sus profesores. 


\section{lasmatematicas.es}

Polémica

\section{El complejo examen de Matemáticas de Selectividad deja un suspenso general}

La nota media de 4,5 es la más baja de la década y complicará el acceso del alumnado valenciano al Grado de Medicina 


\section{lasmatematicas.es}

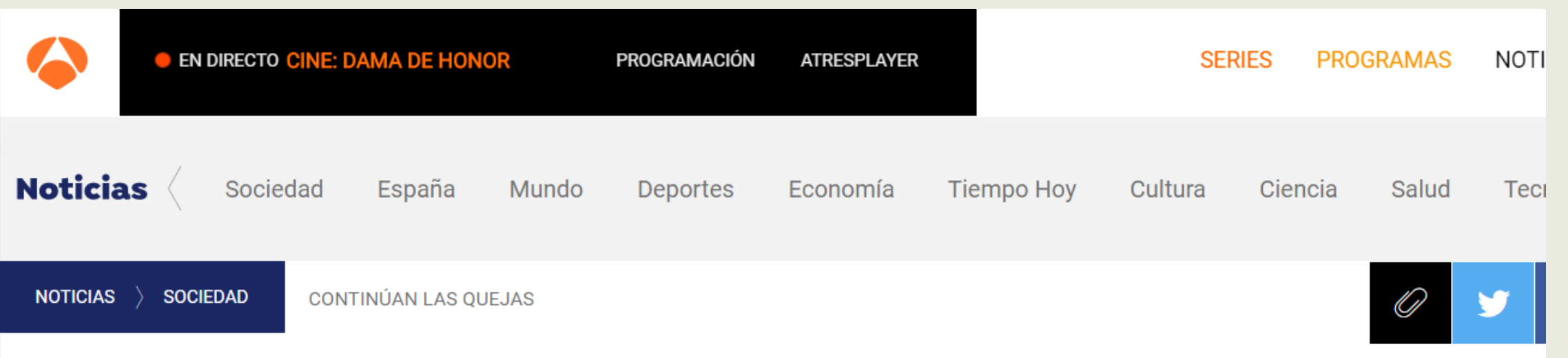

\section{Los estudiantes valencianos se concentran para}

protestar por el examen de matemáticas de la EvAU

Los estudiantes de la Comunidad Valenciana creen que el examen fue extremadamente difícil y temen que las malas notas les impidan acceder a las carreras a las que aspiran: "Se ha hecho para penalizar y para eliminar a cientos de miles de jóvenes de poder acceder a la universidad pública". 


\section{lasmatematicas.es}

Salía un ejercicio de Teorema de Rolle, hacía muchos años que no ocurría.

Salía un ejercicio de "Física", donde lo único que tenían que aplicar es $\mathrm{e}=\mathrm{v}^{*} \mathrm{t}$

Salía una ecuación matricial, donde había que pensar "un poquito". 


\section{lasmatematicas.es}

oyecto pionero de vídeos de atemáticas (diciembre 2005).

ás de 4000 vídeos (secundaria y iversidad).

anal en YouTube educativo

onero (agosto 2006), más de 200

il suscriptores y 70 millones de producciones.

\section{lasmatematicas.os}

Inicio

Contenidos

Sobre mi

You

Tube

Estás en: Inicio

66

La labor del profesor no es demostrar lo que sabe, es transmitirlo"

Las matemáticas no me entran, $\mathrm{i}$ Eso es un tópico, y vamos a acabar con él!!

las matematicas.es Portal de matemáticas completo para aprender desde sumar fracciones hasta resolver ecuaciones diferenciales.

Contenidos:

- Contenidos de Matemáticas de educación secundaria. (Muchos

- Vídeos de problemas y
docarrnllne tońrimé do

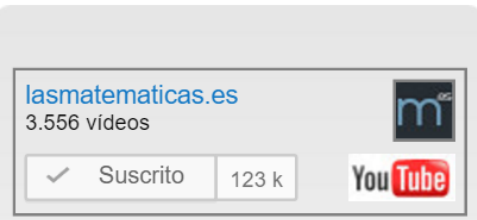




\section{lasmatematicas.es}

Durante muchos años no me ha preocupado en exceso la estética de mis vídeos, ni títulos, ni miniaturas, me he centrado en la calidad académica de mi material.

Sin embargo, hay que atraer a los estudiantes, para engancharlos. 


\section{lasmatematicas.es}

Vídeos "a mano alzada".

Emplear el tiempo justo (cuesta generar el vídeo tanto como dura).

Es la forma tradicional de presentar los contenidos (clase magistral).

Ir desarrollando el contenido permite que el alumno lo vaya asimilando poco a poco.

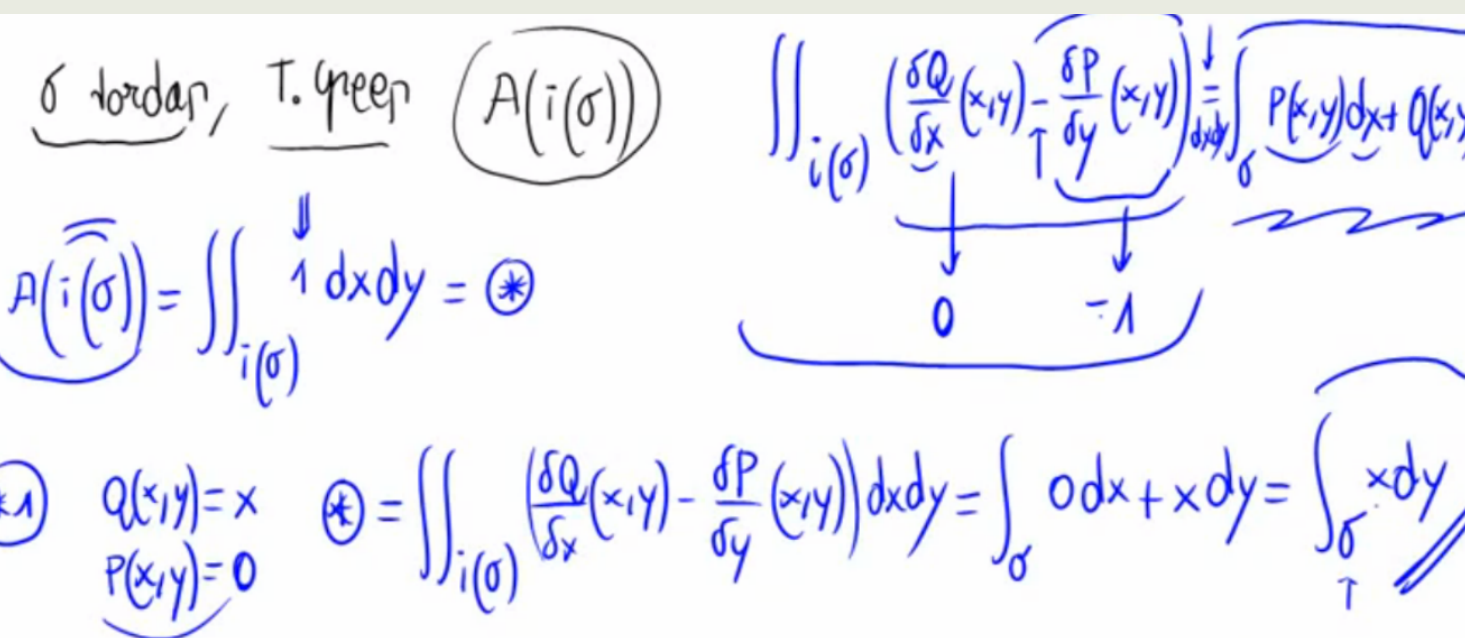

$$
\begin{aligned}
& \text { (*2) } \left.\begin{array}{l}
Q(x, y)=0 \\
P(x, y)=-y
\end{array} \circledast \int_{\sigma}(-y d x+0 d y)=\int_{\sigma}-y d x \quad A(i(\sigma))\right)_{N}^{\prime \prime} \int_{\sigma}^{\prime}
\end{aligned}
$$




\section{rocedimiento inicial para la generación de vídeos}
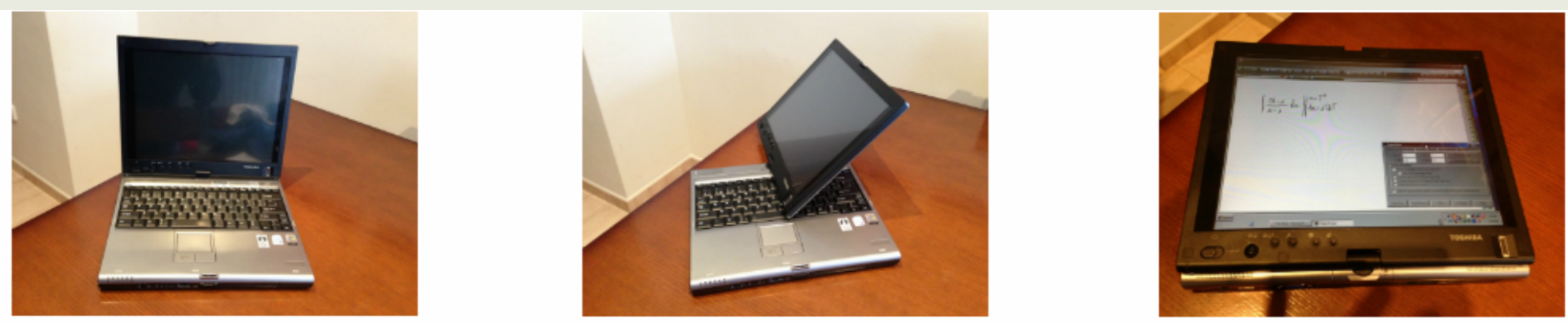

Tablet PC, Surface Pro, Tableta (Wacom,...) 


\section{EM \\ yme}

Portal de Moocs con contenidos de secundaria.

Ciencia, Tecnología, Ingeniería y Matemáticas.

Matemáticas y Cinemática.

\section{STEM}

INICIO CURSOS

NO'TE QUEDES CON DUDAS

IENTRA A PROEE S:O.S.

PREGUNTA Y APRUEBA:

REGísTRATE

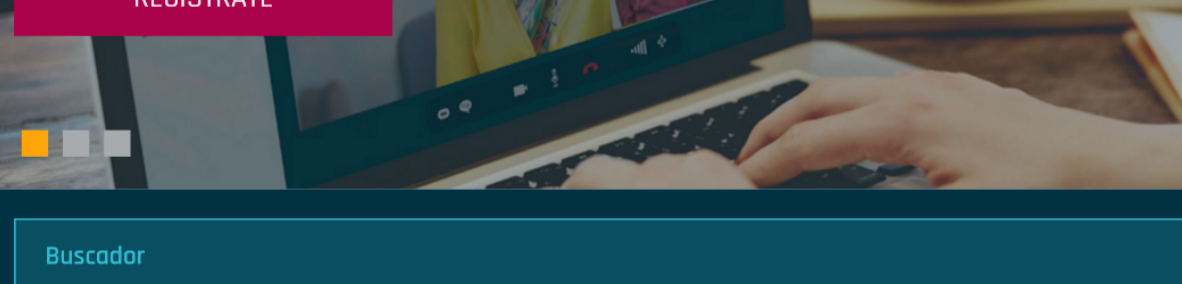




\section{EM \\ yme}

\section{STEM}

No sirve "Letra a mano alzada".

Word y editor de ecuaciones. NO

LaTeX

NO TE QUEDES CON DUDAS

IENTRA A PROFE S:O.S.,

PREGUNTA Y APRUEBAI:

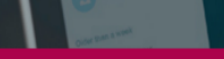

REGÍSTRATE

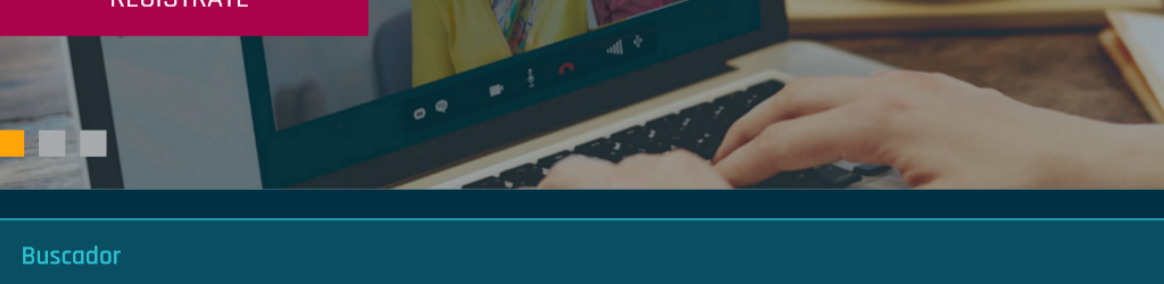




\section{ídeos con LaTex}

\section{irabación del audio}

\section{Elementos de un problema de programación lineal}

Programación lineal

Dos variables: $x, y$

Máximos o mínimos

$f(x, y)=a x+b y$

$a, b \in \mathbb{R}$

Función objetivo

Restricciones $\longrightarrow$ Región factible

$\leq \geq$

\section{$\operatorname{MAX}-2 x+3 y$}

s.a.:

$$
\begin{gathered}
3 x+2 y \leq 6 \\
-2 x+y \geq-2
\end{gathered}
$$$$
x \geq 0
$$

A Audacity

Archivo Editar Ver Control Pistas Generar Efecto Analizar Ayuda

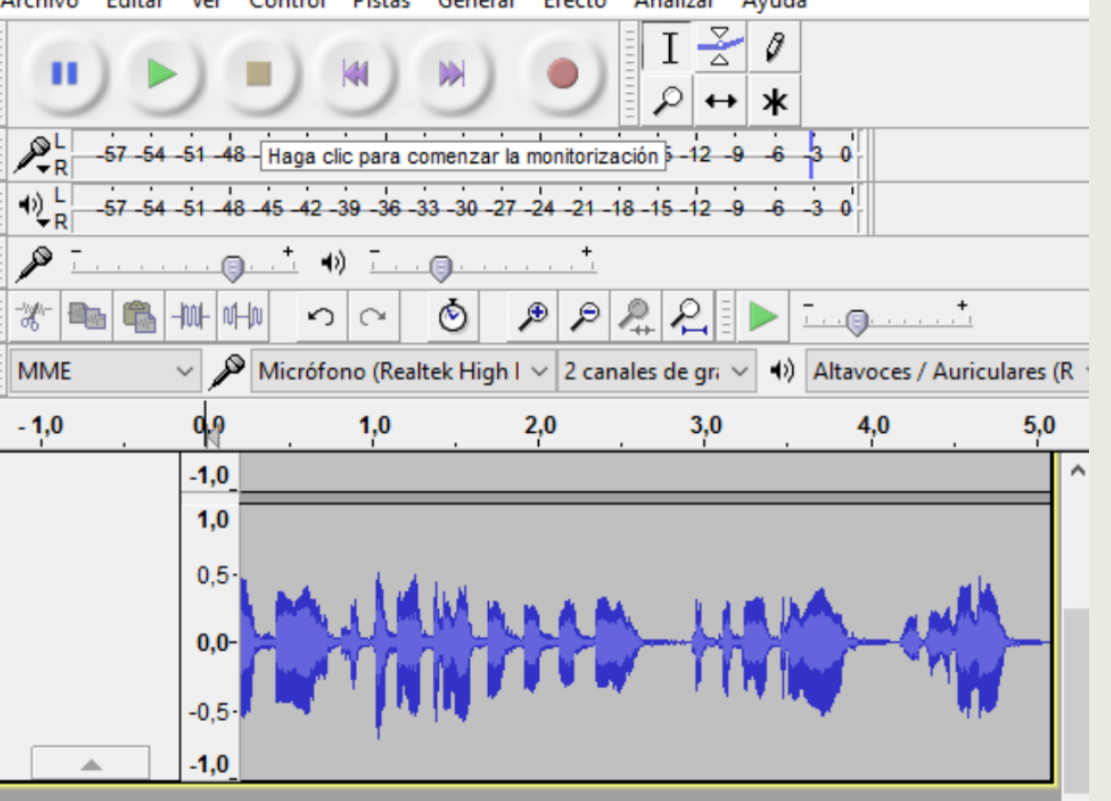
$<$

Frecuencia del proyecto $(\mathrm{Hz})$ : Ajustar Comienzo de la selección: $\bigcirc$ Flnal O Longituc Apagado $00 \mathrm{~h} 00 \mathrm{m00.000 \textrm {s }} 00 \mathrm{h00 \textrm {m00.00 }}$ 
$\rightarrow \longrightarrow \longrightarrow+X \quad-X$

... enbla... enbla... flecha... flech... graf2a... graf3a... grafa.... grafb... grafc....

$X-X=\Rightarrow-1=0$

.. grafe.... graff.... igual.... implic... introa... introa... introb... introc... introd...

$=\left\{\begin{array}{l}- \\ +\end{array}\right.$

introf... $\|$ laves... mas.... max... men... perio... prueb... titulo...

\section{$\Delta \Delta$}

video... video..

\section{Elementos de un problema de programación lineal}

Programación lineal Dos variables: $x, y$

Máximos o mínimos $f(x, y)=a x+b y \quad a, b \in \mathbb{R}$

Función objetivo

Restricciones $\longrightarrow$ Región factible

$\leq \geq$

$\operatorname{MAX}-2 x+3 y$

s.a.:

$3 x+2 y \leq 6$

$-2 x+y \geq-2$
$x \geq 0$

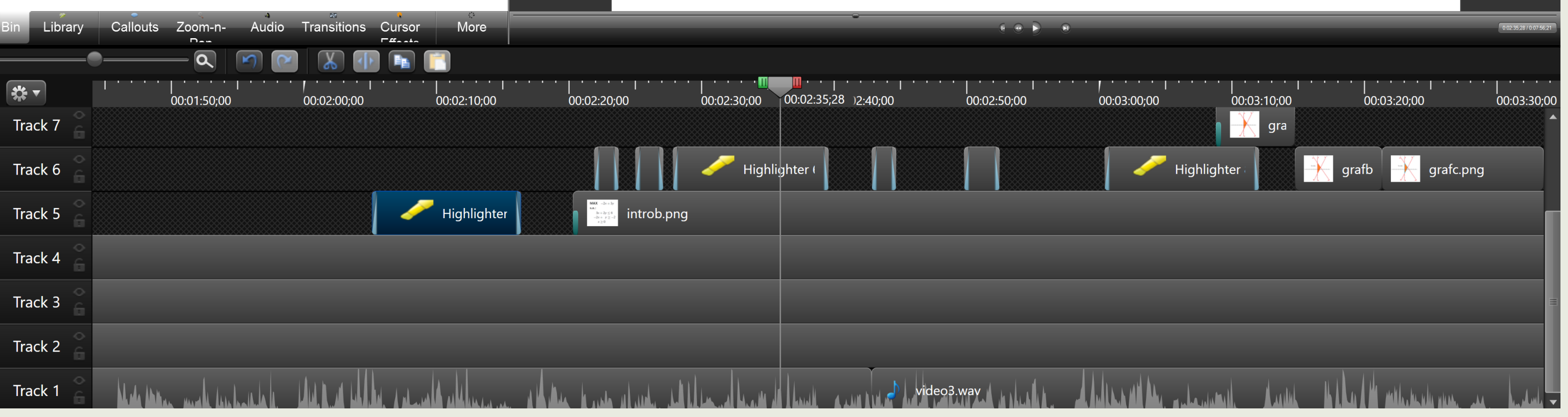


$\prime-2 y=2 x \mathrm{e}^{2 x} \quad \mathcal{L}\left[x^{n} \mathrm{e}^{a x}\right]=\frac{n !}{(s-a)^{n+1}}, n \in \mathbb{N}$
$(0)=0$

$\left.y^{\prime}-2 y\right]=\mathcal{L}\left[y^{\prime}\right]-2 \mathcal{L}[y]=s \mathcal{L}[y]-y(0)-2 \mathcal{L} \mid \mathcal{X}=s \mathcal{L}[y]-2 \mathcal{L}[y]=(s-2) \mathcal{L}$

$\left.2 x \mathrm{e}^{2 x}\right]=2 \mathcal{L}\left[x \mathrm{e}^{2 x}\right]=2 \cdot \frac{1 !}{(s-2)^{1+1}}=\frac{2}{(s-2)^{2}}$

$n=1, a=2$

-2) $\mathcal{L}[y]=\frac{2}{(s-2)^{2}} \Rightarrow \mathcal{L}[y]=\frac{2}{(s-2)^{3}} \Rightarrow y=\mathcal{L}^{-1}\left[\frac{2}{(s-2)^{3}}\right]=$

$\mathcal{L}^{-1}\left[\frac{2}{(s-2)}\right]$

$$
n+1=3
$$


ídeos con LaTex

Cuesta muchísimo generar este tipo de material, pero puedo generar rápidamente presentaciones de ejercicios para usar en clase. 
ivulgando en YouTube

Crear vídeos diferentes, donde se muestren las matemáticas sin entrar mucho en los detalles pero sin perder el rigor.

Incluir esas explicaciones que damos tras presentar una definición o propiedad. 
ivulgando en YouTube

Formato más cuidado.

Aparezco en pantalla. 


\section{ivulgando en YouTube}

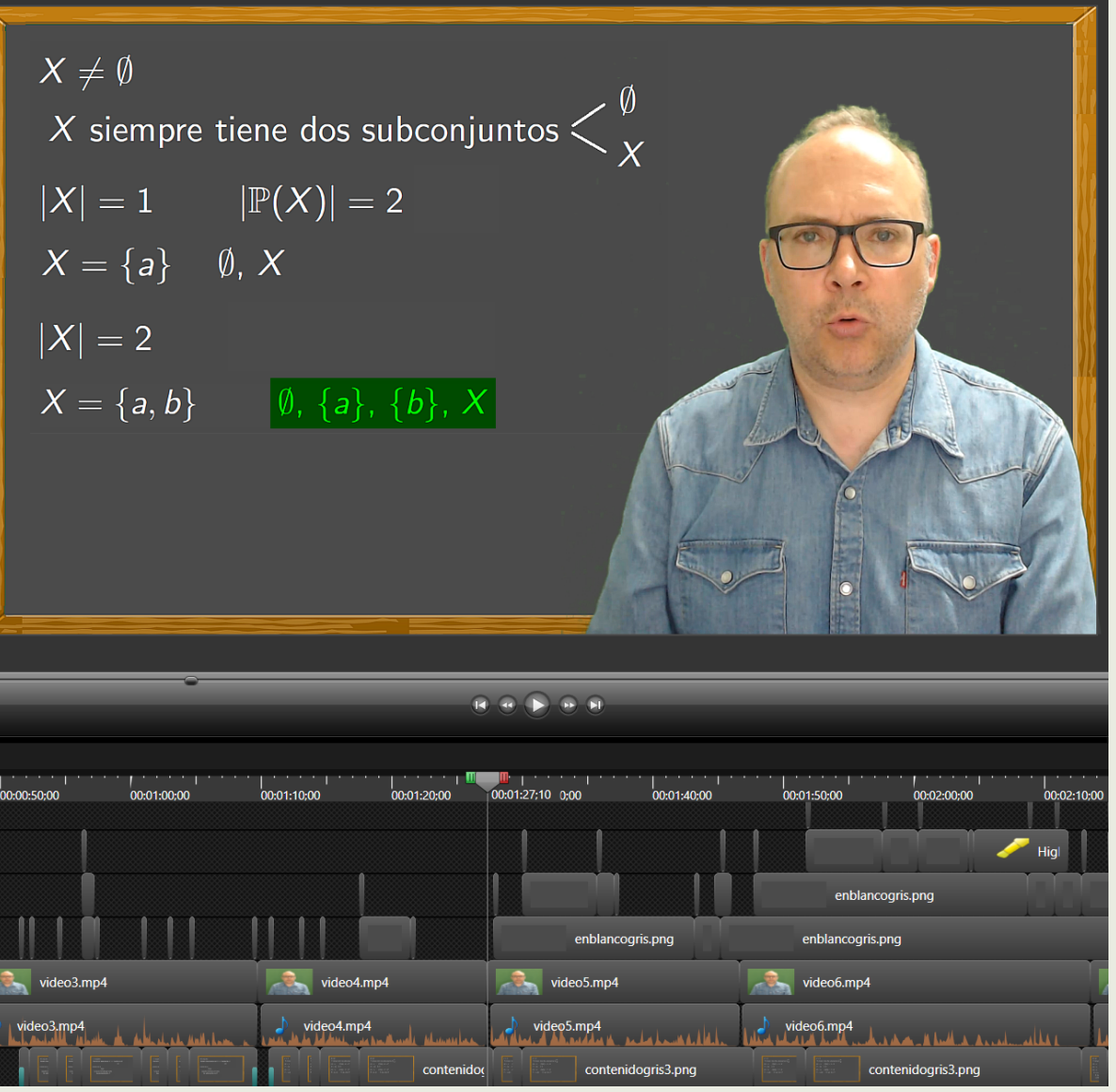


ivulgando en YouTube

1. Texto del guión, en párrafos.

2. Grabar vídeos con fondo verde (uno por párrafo).

3. Presentación en LaTeX.

4. Edición del vídeo, con Camtasia. Estructura: INTRO + Cortinilla + Desarrollo + Cortinilla

5. Incorporar música de fondo.

6. Miniatura para Twitter y para YouTube. 


\section{ivulgando en YouTube}

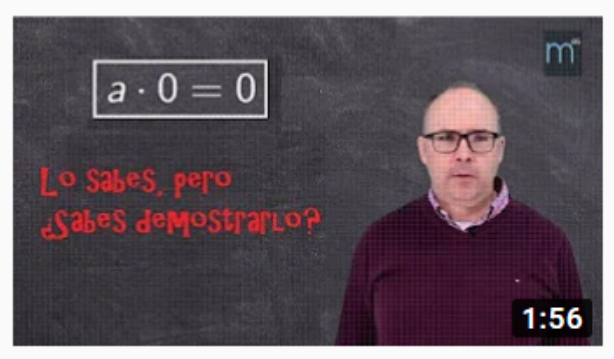

$\mathrm{n}^{\text {es }}$ Desentranando La deFincion de LiMpte $\lim f(x)=1$ Para cada $\epsilon>0$ existe $\delta>0$ tal iो Para cada $\epsilon>0$ existe $\delta>0$ tal
que six $\in$ Dom $f, 0<\left|x-x_{0}\right|<\delta$ entonces $f(x)-1$

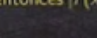
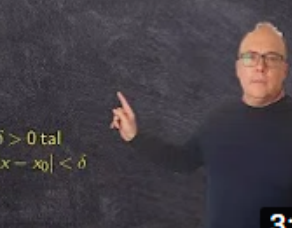

3:51

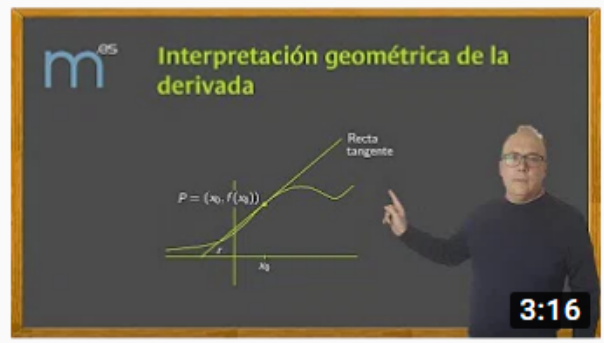

Ya sabes que a por 0 es 0 , pero ¿sabes demostrarlo?

lasmatematicas.es $\bullet$ 6,8 mil visualizaciones $\cdot$ Hace 6 meses

Demostramos que a por 0 es 0 . Suscríbete a nuestro canal y recibe notificaciones con nuestras nuevas publicaciones: ...

Desentrañando la definición de límite de una función, limites de funciones lasmatematicas.es $\bigcirc 4,1$ mil visualizaciones $\cdot$ Hace 4 meses

Interpretamos la definición de límite de una función en un punto, sí, la de epsilon y delta, para que resulte comprensible.

Interpretación geométrica de la derivada, derivadas de funciones de una variable

lasmatematicas.es $\bullet \quad 2,7$ mil visualizaciones $•$ Hace 3 meses

Presentamos la interpretación geométrica de la derivada en poco más de 3 minutos, te va a quedar clarísimo. Míralo, prohibido .. 


\section{ivulgando en YouTube}
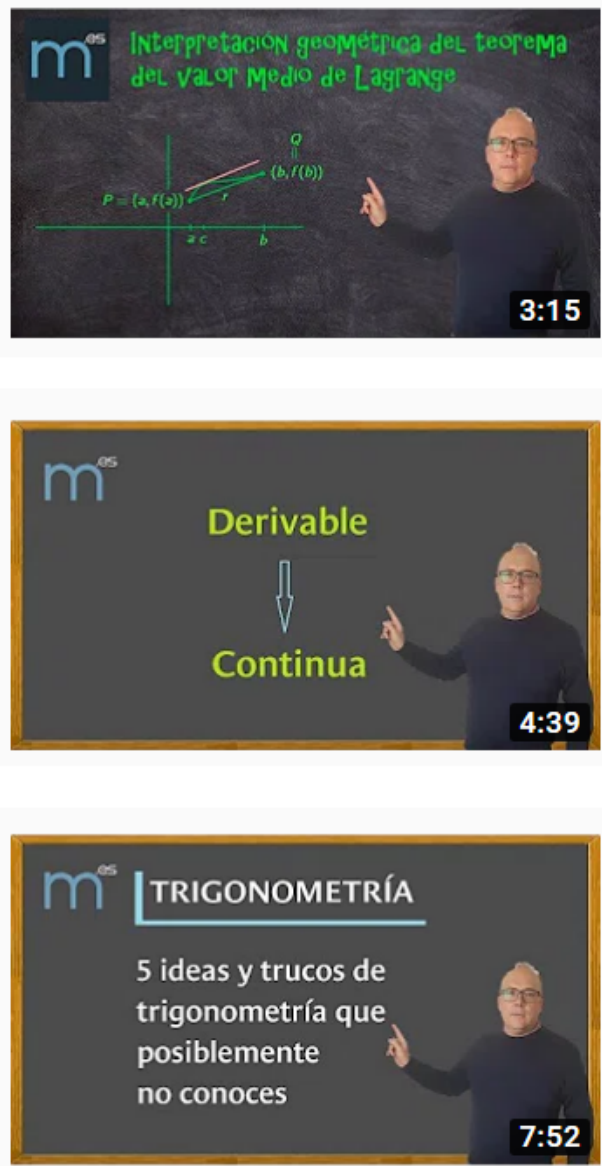

Interpretación geométrica del Teorema del valor medio de Lagrange, derivadas, recta tangente

lasmatematicas.es $\bullet$ 2,1 mil visualizaciones $•$ Hace 4 meses

Presentamos la interpretación geométrica del teorema del valor medio de Lagrange, un resultado muy importante de funciones ...

Subtítulos

Derivable implica continua, toda función derivable en un punto es continua en dicho punto

lasmatematicas.es $\bullet$ 1,5 mil visualizaciones $•$ Hace 3 meses

En este vídeo demostramos que toda función derivable en un punto en un punto es continua en dicho punto, y además...

5 ideas y trucos de trigonometría que posiblemente no conoces lasmatematicas.es $\bullet$ 4,7 mil visualizaciones $\cdot$ Hace 3 meses

Presentamos 5 ideas y trucos sobre trigonometría que debes recordar, porque después de un examen es cuando más sabe,s... 


\section{ivulgando en YouTube}
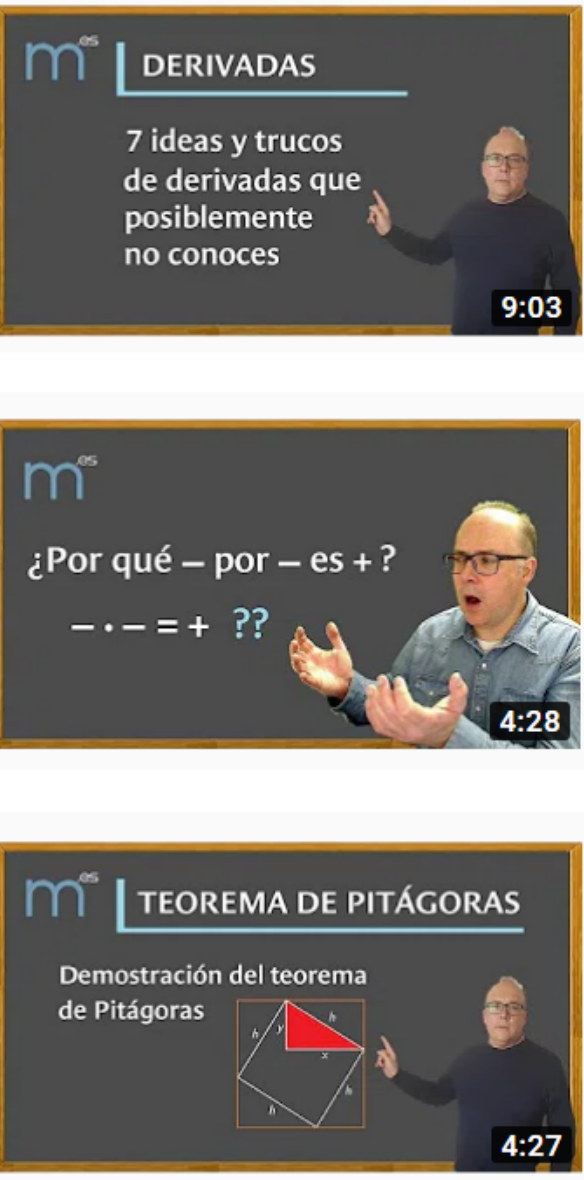

7 ideas y trucos sobre derivadas que posiblemente no conoces lasmatematicas.es $\bullet 4,4$ mil visualizaciones $\cdot$ Hace 2 meses

Presentamos 5 trucos e ideas de derivadas que debes saber, como profesor en la universidad veo que mis alumnos suelen fallar ...

¿Por qué MENOS por MENOS es MÁS? La demostración más sencilla en solo 4 minutos

lasmatematicas.es $\bullet 9$ mil visualizaciones $•$ Hace 2 meses

Demostramos que menos por menos es más de forma rigurosa, trabajando con opuestos, lo vas a entender perfectamente.

Demostración del Teorema de Pitágoras apta para todos los públicos shurprofe $\cdot 2,8$ mil visualizaciones $\cdot$ Hace 2 meses

Presentamos una demostración básica del teorema de Pitágoras, el teorema más famoso de las matemáticas, es un ... 


\section{ivulgando en YouTube}
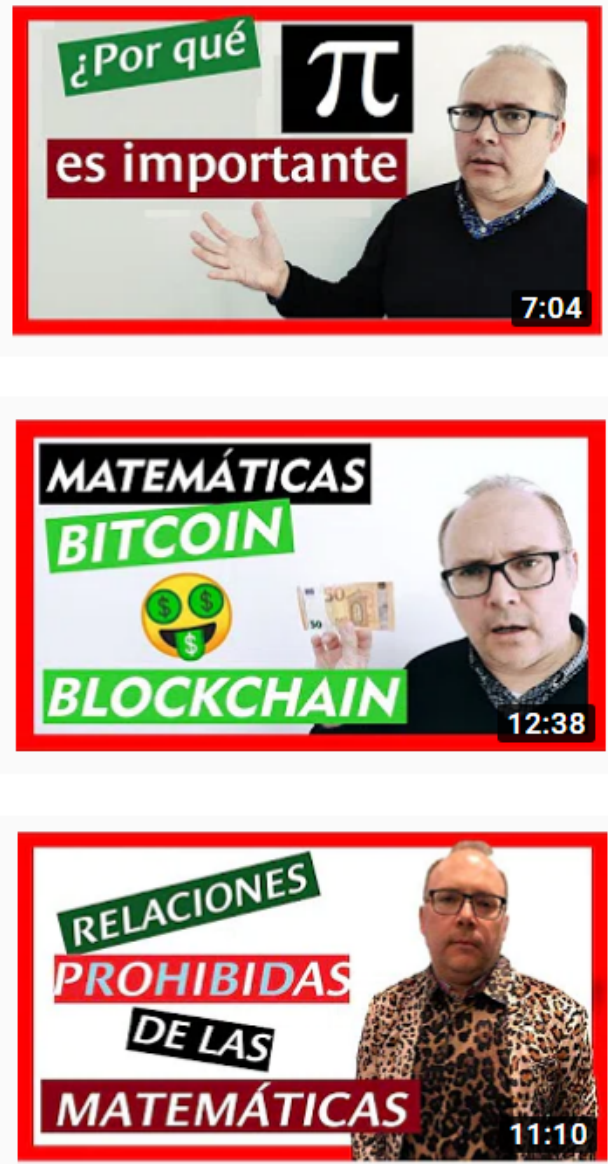

¿Por qué PI siempre vale lo mismo? Demostramos que número PI es constante \#PiDay \#PiDay2019 \#DiaPi

lasmatematicas.es $\bullet$ 3,6 mil visualizaciones • Hace 2 meses

Todos asumimos que pi, la división de la longitud entre el diámetro de una circunferencia, no depende de la circunferencia, esto ...

Bitcoin, blockchain y sus matemáticas, explicado de forma fácil,

Criptomonedas, criptografía

lasmatematicas.es $\bullet \quad 3,8$ mil visualizaciones • Hace 2 meses

Contamos de forma cercana y sencilla que matemáticas aparecen en el bitcoin, blockchain, realizando un repaso de criptografía ..

Las relaciones prohibidas de las matemáticas lasmatematicas.es $\bullet$ 2,5 mil visualizaciones $•$ Hace 2 meses

En este vídeo hablamos sobre un tipo de relaciones que se satisfacen en determinados famosos elementos, pero sin embargo, ... 


\section{ivulgando en YouTube}
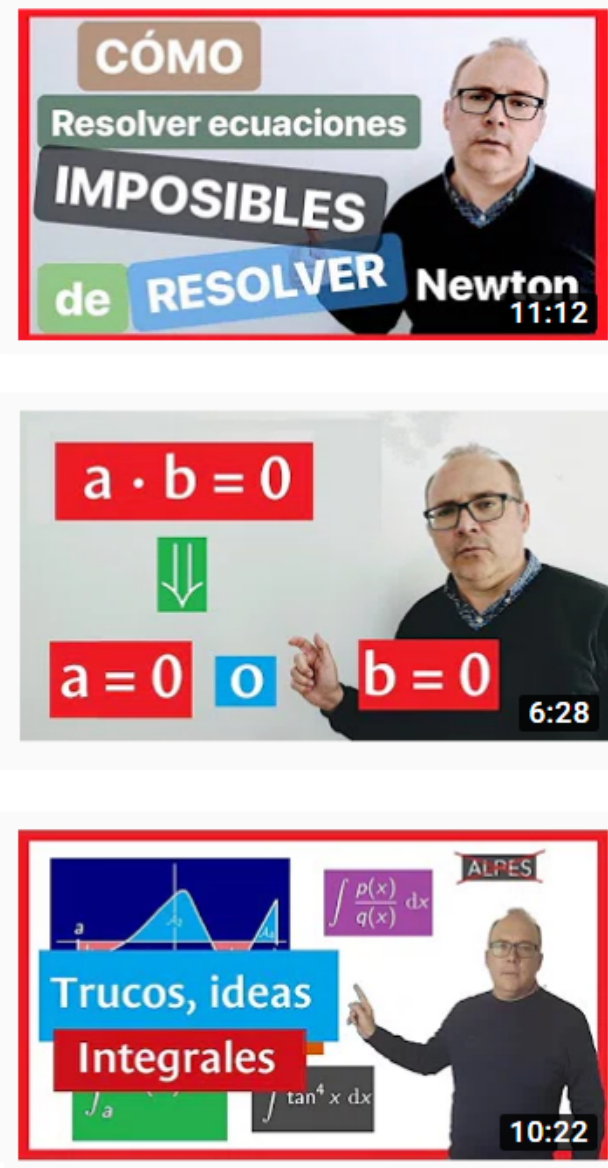

Cómo resolver ecuaciones IMPOSIBLES de resolver, Método de Newton, resolución numérica de ecuaciones

lasmatematicas.es $\diamond 5$ mil visualizaciones $\cdot$ Hace 1 mes

Introducimos el método de Newton para la resolución numérica de ecuaciones, deduciendo con todo detalle la fórmula. Accede a ...

a por b cero implica a cero o b cero. Aprender a hacer demostraciones matemáticas, disyunción

lasmatematicas.es $\bullet$ 1,3 mil visualizaciones $\cdot$ Hace 1 mes

Demostramos una propiedad que dice que si a por b es cero, entonces a es cero o b es cero. Veremos que el o matemático o de la ..

5 TRUCOS e ideas de INTEGRALES que debes conocer lasmatematicas.es $\bullet 1,5$ mil visualizaciones $\cdot$ Hace 3 semanas

Presentamos 5 trucos e ideas de integrales y cálculo de primitivas que te van a venir genial para repasar el cálculo de integrales ... 


\section{ivulgando en YouTube}
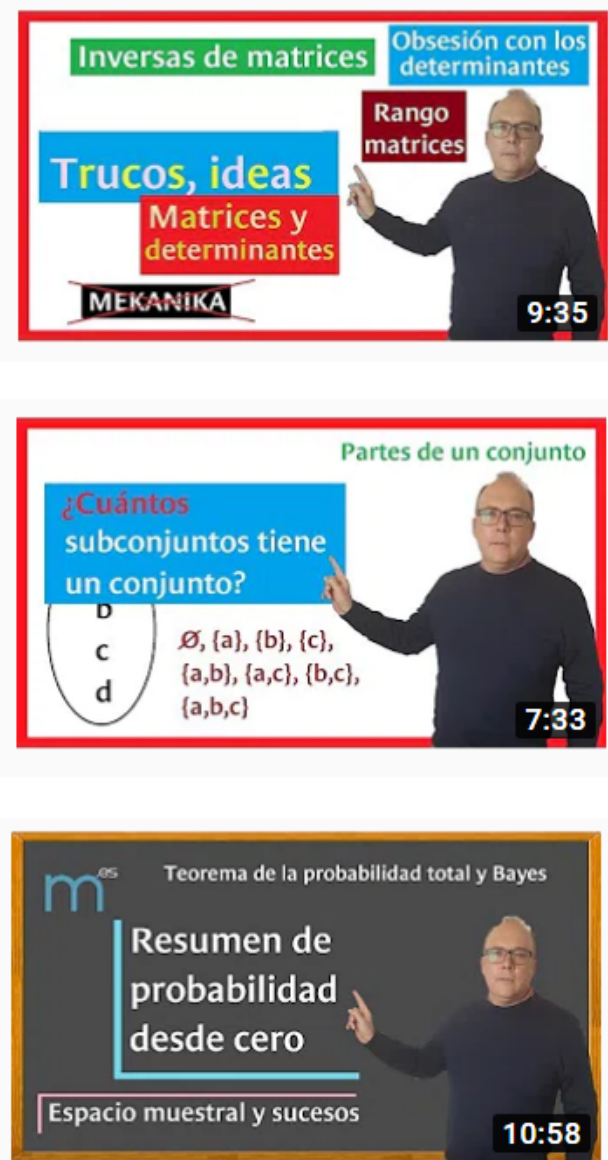

5 TRUCOS e ideas de MATRICES y DETERMINANTES que debes conocer lasmatematicas.es $\bullet 586$ visualizaciones $\cdot$ Hace 2 semanas

Presentamos 5 ideas y trucos de matrices y determinantes que van a venirte genial como un repaso perfecto. Rango de matrices...

¿Cuántos subconjuntos tiene un conjunto? Aprender a realizar demostraciones, conjuntos

lasmatematicas.es $\odot 684$ visualizaciones $\cdot$ Hace 1 semana

En este vídeo deduciremos, aplicando la fórmula del binomio de Newton, cuántos subconjuntos tiene un conjunto finito.

Probabilidad en 10 minutos, desde cero hasta el teorema de probabilidad total y Bayes

lasmatematicas.es $\bullet 674$ visualizaciones $•$ Hace 5 días

El mejor resumen de probabilidad desde cero hasta llegar al teorema de la probabilidad total y teorema de Bayes, paso a paso.

Nuevo 
olviendo a los orígenes

Grabar uno de estos vídeos puede llevarte varios días a jornada completa...

Volver a mano alzada, pero con una edición más cuidada. 
olviendo a los orígenes

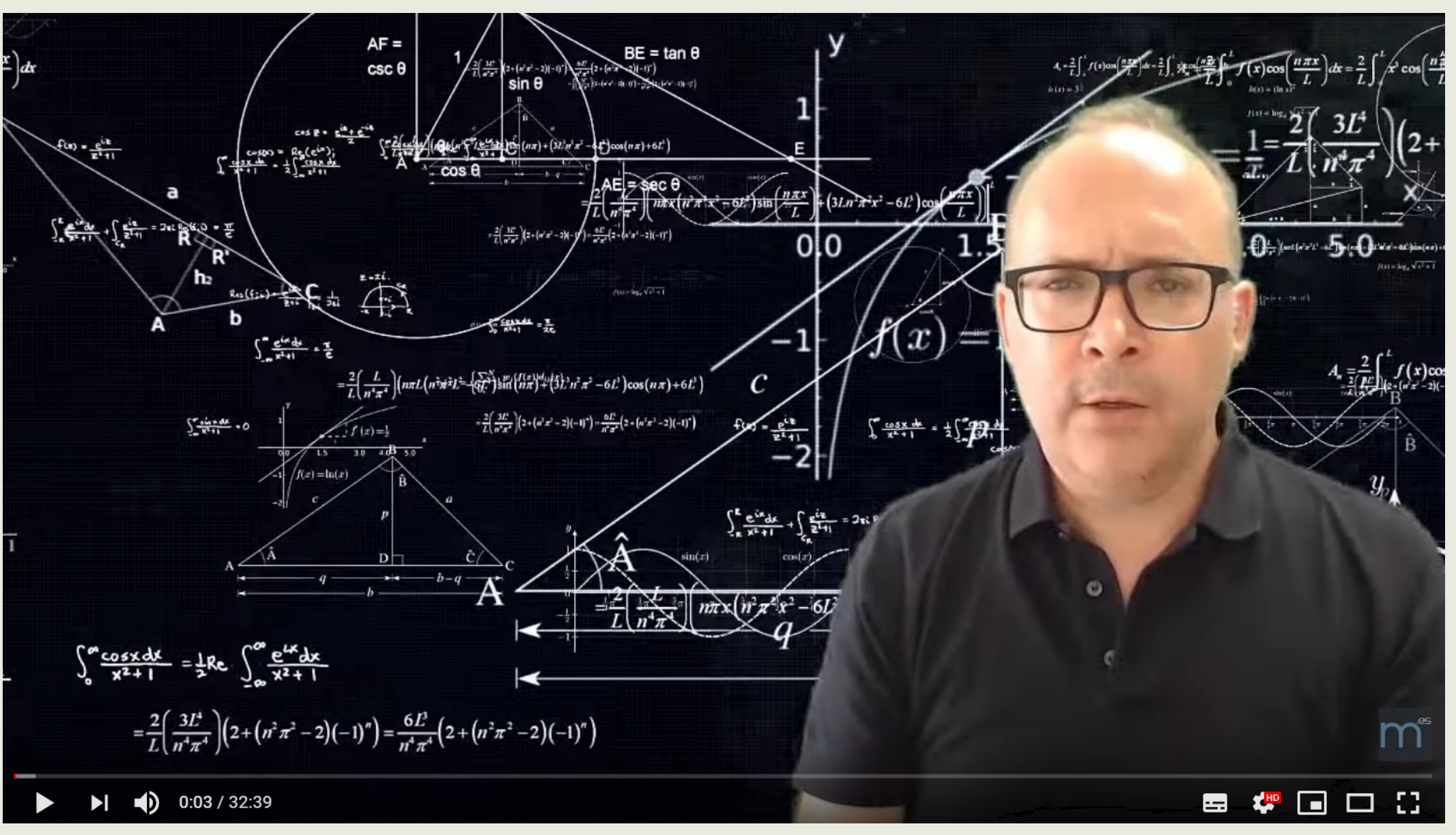


olviendo a los orígenes

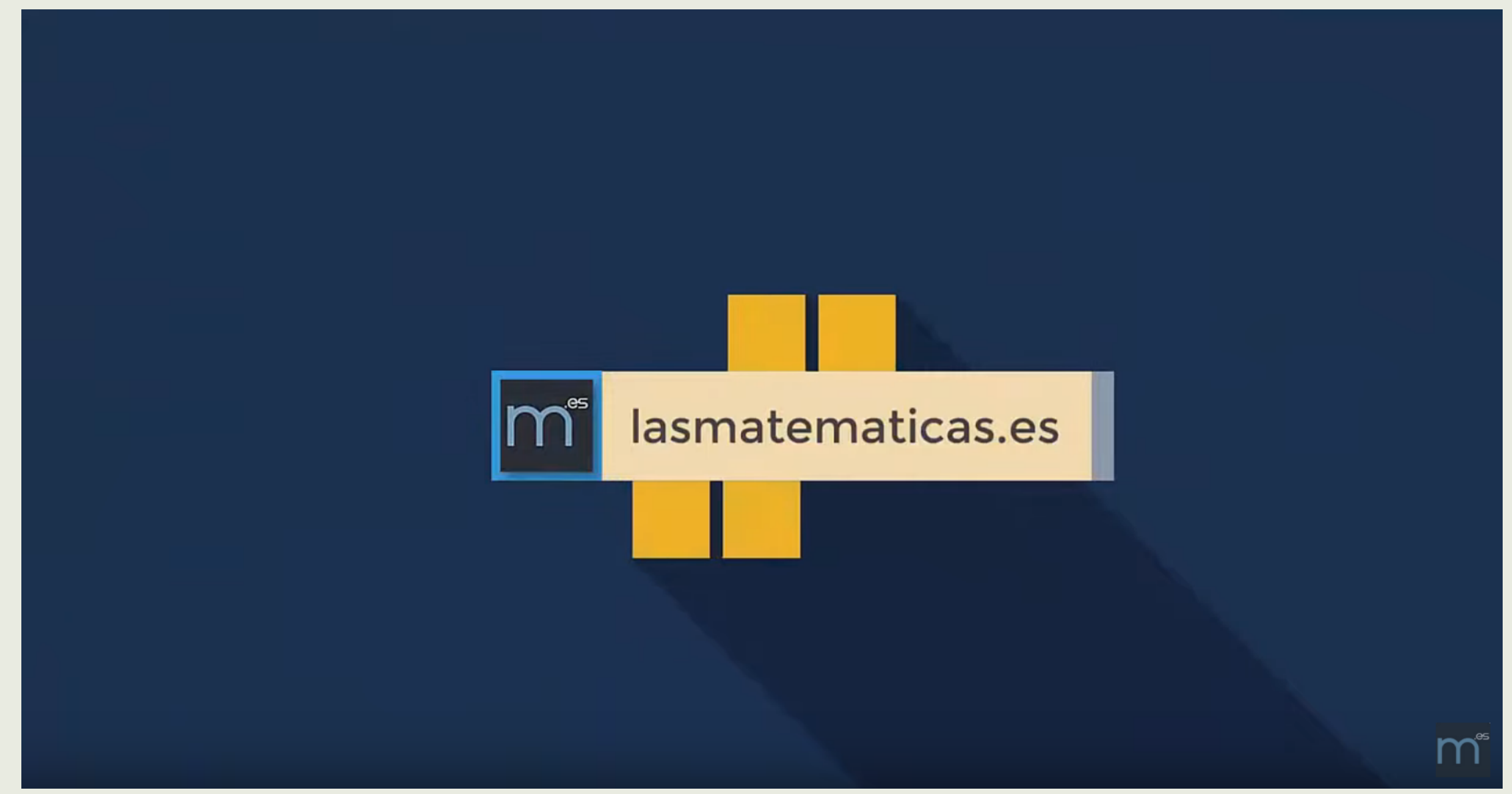




\section{olviendo a los orígenes}

$f: \mathbb{R}^{3} \longrightarrow \mathbb{R}^{3}$ epdocuorfijuro / $f(x, y, z)=(x-y+2 z,-x-y-z,-2 y+z)$ $B=\{(-1,1,0),(2,-1,-1),(0,1,0)\}$ beje de $\mathbb{R}^{3}$

d) $M_{C}(f)$ y $M_{B}(f)$.

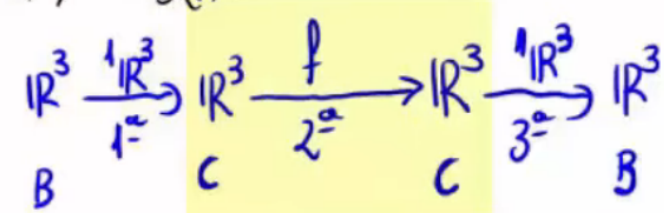
$n(f)=\left(\begin{array}{ccc}1 & -1 & 2 \\ -1 & -1 & -1 \\ 0 & -2 & 1\end{array}\right)$

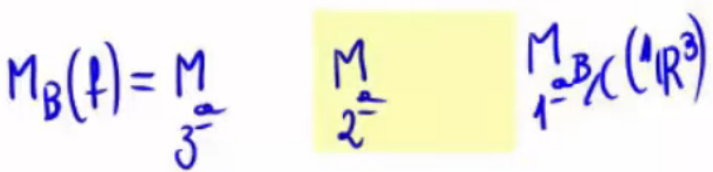




\section{ídeos en catalán}

royecto con Guillem de la Calle y Javi Tejedor:

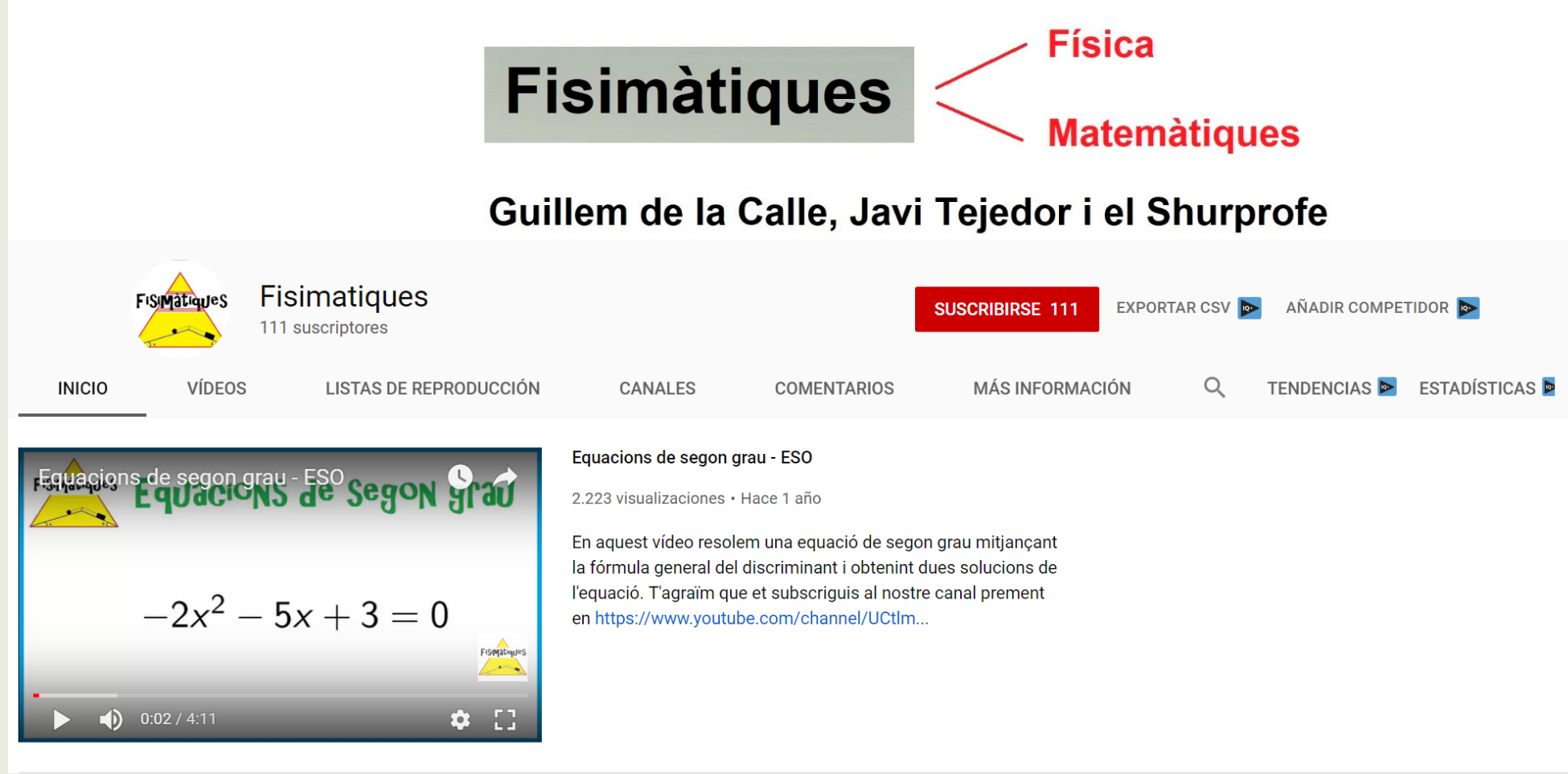




\section{ídeos en euskera}

\section{royecto con Julen Bengoa:}

\section{Matematika GuNea}

\section{Julen Bengoa eta Shurprofe}

Vídeos subidos $\longrightarrow$ REPRODUCIRTODO

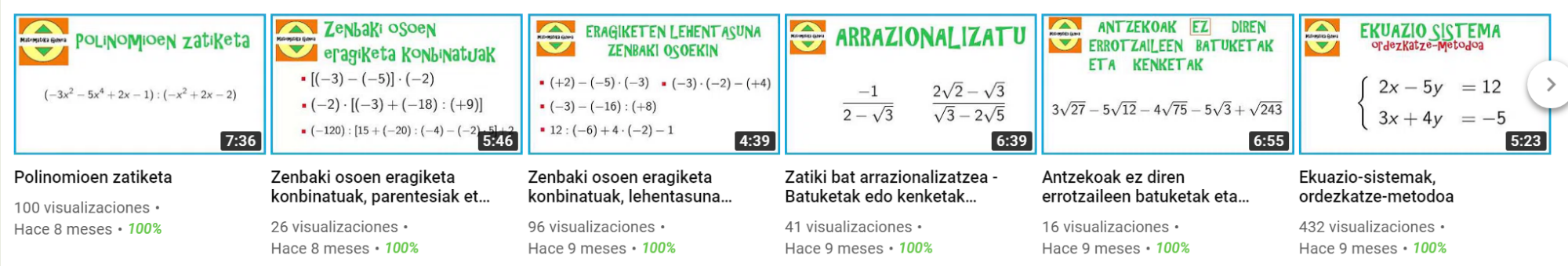


ídeos en inglés

David Darling, astrofísico (Universidad de Manchester) y escritor.

Traducción de algunos de mis últimos vídeos.

Creación de nuevos vídeos 
ídeos en inglés

1. Traducción y adaptación del guión.

2. Narración.

3. Edición con Camtasia. 


\section{ídeos en inglés}
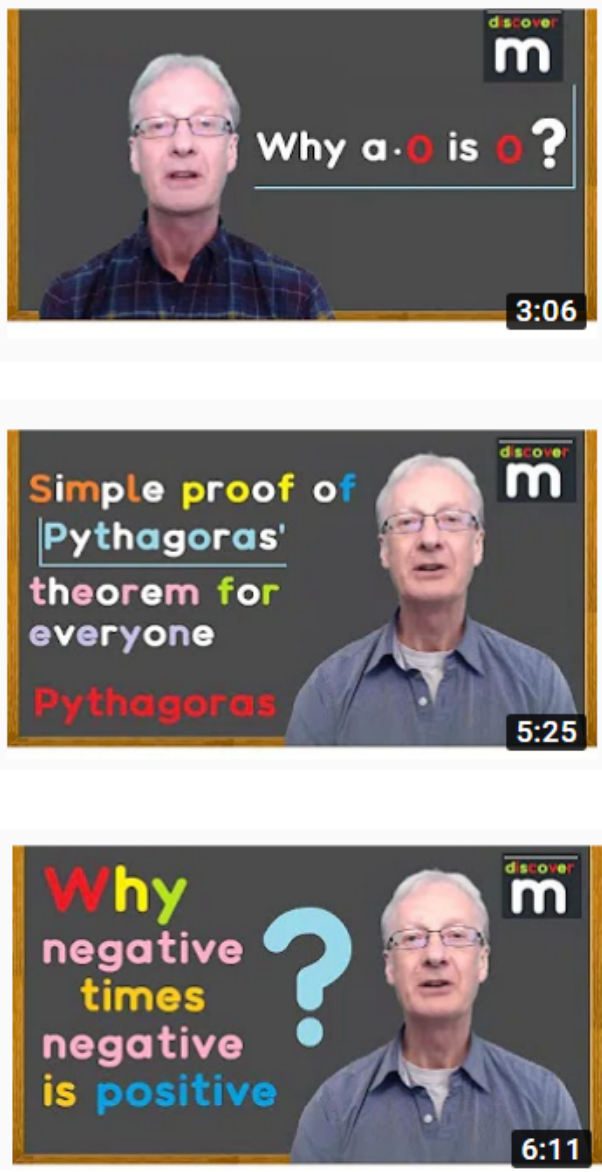

Why is any number multiplied by zero 0 ? A mathematical proof using the properties of real numbers.

discovermaths $\cdot 647$ visualizaciones $•$ Hace 3 semanas

In this video we show that when multiplying any number by 0 the result is 0 . For this we use some axioms of real numbers: the ...

Simple proof of Pythagoras' theorem for everyone discovermaths $\cdot 478$ visualizaciones $\cdot$ Hace 1 semana

In this video, we demonstrate in just 5 minutes the most famous theorem of mathematics, the lue Pythagoras theorem.

Why is a negative number times a negative number positive? discovermaths $\cdot 142$ visualizaciones • Hace 2 días

In this video we show, step by step, that when multiplying a negative number by a negative number the result is always a positive...

Nuevo 


\section{ídeos en inglés}
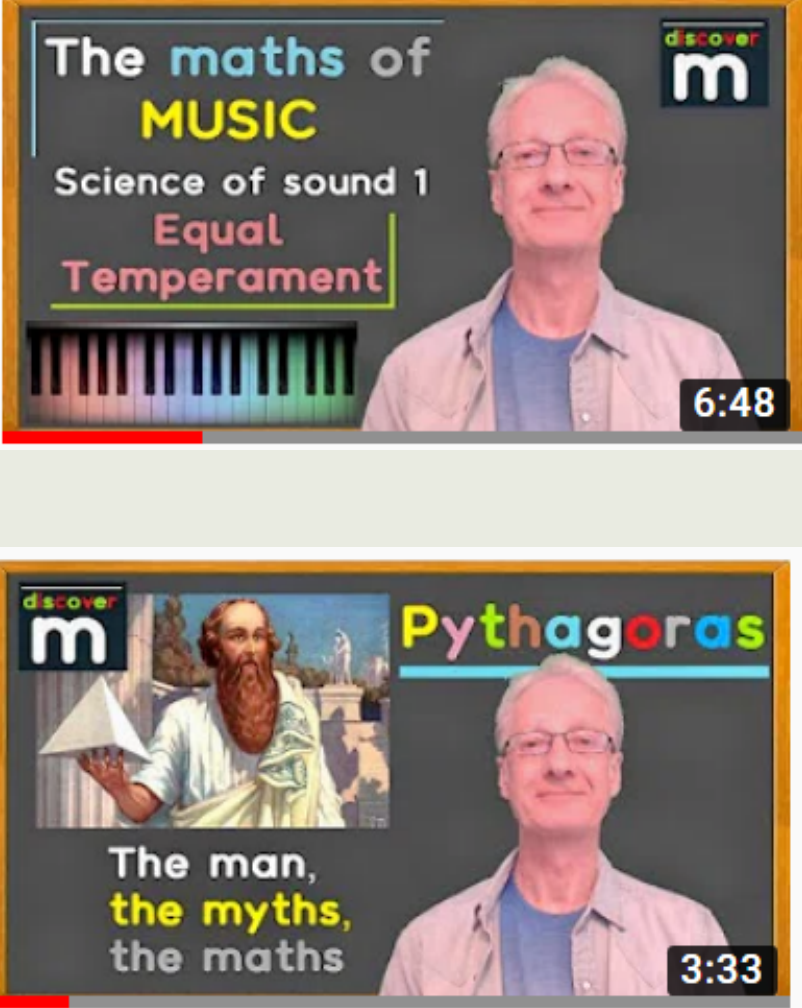

\section{Equal temperament (Maths of music, science of sound 1)}

discovermaths $\cdot 260$ suscriptores 130 visualizaciones $\cdot$ Hace 1 día $\cdot 100 \%$

The tuning system known as equal temperament is almost universally used in modern Western music. But what is it and what's the ...

Nuevo

\section{Pythagoras: the man, the myths, the maths}

discovermaths $\cdot 260$ suscriptores 165 visualizaciones $\cdot$ Hace 1 mes $\cdot 100 \%$

We've all heard of Pythagoras's theorem, but who was Pythagoras and what do we really know about him? 


\section{Grabando vídeos educativos desde 2005}

¡iGRACIAS POR VUESTRA ATENCIÓN!! 